Hairs and pubescence golden yellow, both poorly developed on the head, more abundant on the body and legs; the hairs erect, rather fine, moderately long, the pubescence long and rather coarse, not very closely appressed.

Ferruginous; legs and antennæ scarcely paler; head and mandibles a little darker, in some specimens with the occiput slightly infuscated.

Redescribed from four specimens taken August 30, 1919 by the junior author near Camden, Tennessee. The specimens were found four miles west of the town on a rather dry hillside covered with an open forest of second growth oak. The trees were small and so scattered that there was a ground cover of short wiry dry grass under them, with a few small shrubs and bushes. There was very little ground débris, as the natives seem to keep such picked up for firewood, but under a small stick, perhaps two feet long and three inches wide at its greatest width all four of the ants were found. The stick had evidently been lying in one position for a long time, as it was slightly buried, so that it came up with difficulty and disturbed the earth in loosening. The ants were in the soil beneath the stick, close together, but no evidence of a nest was seen. They were very sluggish and slow-moving, even more so than a few specimens of Stigmatomma pallipes Haldem, which were found in the same habitat. They made no effort to escape, seemed dazed and confused by the sudden disturbance, and one of them when picked up with the forceps and placed in the palm of the hand, feigned death for several seconds, with the antennæ drawn close to the head and the legs held tightly against the body.

\title{
NOTE ON PTERERGATES IN THE CALIFORNIAN HARVESTER ANT.
}

\section{By Harlow Shapley,}

Mount Wilson Observatory, Pasadena, California.

The phenomenon of vestigial wings in worker ants that otherwise are normal is of interest because of its significance in the problem of the origin of social castes among the Formicidæ, and also because of its infrequent occurrence. The recorded captures of workers with wing-vestiges are very few. Wheeler has taken three 
pterergates in New York from a colony of Myrmica scabrinodis var.; Keys found one of the same species in England (figured in Donisthorpe's British Ants, p. 41). Wheeler has also taken a large worker with vestigial wings from a colony of Cryptocerus aztecus in Mexico, and Bondroit found at Landelies in Belgium one pterergate of the species Lasius flavus.

One of the most common ants in Pasadena at the present time is the large red harvester, Pogonomyrmex californicus Buckley, but apparently it is being exterminated by Iridomyrmex humilis Mayr, the rapidly spreading Argentine ant. From one of the small embattled nests of $P$. californicus which has been under observation since March, 1919, I sent a few specimens to Professor Wheeler, who called my attention to the presence of three pterergates. Further investigation has shown that of all the workers of this nest

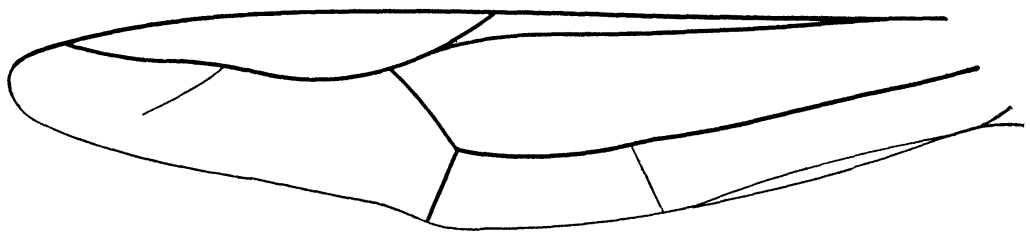

Fig. 1. Vestigial anterior wing of a worker of Pogonomyrmex californicus Buckley.

seen during 1919 one-half has vestigial wings, varying in degree of development from small chitinous nodules on the mesothorax to membranous structures one to two millimeters in length. Except for these organs representing wings, there is no conspicuous difference in thoracic structure, or otherwise, between the pterergates and the remainder of the workers.

The vestiges observed in all six of the pterergates mentioned in the first paragraph are on the mesothorax, and indicate the abnormal development of anterior wings. There is also but a single pair of vestiges for sixteen of the pterergates of $P$. californicus so far examined.

One individual from this nest, however, is unique, not only in having vestiges both of anterior and of posterior wings, but also in possessing one anterior wing that is membranous and veined. A diagram of the venation of this most developed wing, which resembles more closely that of a normal hind wing, is given in 
the accompanying figure. At the time of capture the pterergate was beset by a half dozen Argentine ants; it is quite possible, therefore, that the other anterior wing had been pulled off in the course of this last fight or during previous activities.

\section{SIBERIAN ANOPHELES.}

By C. S. Ludlow, Army Medical Museum, Washington, D. C.

The collections of mosquitos sent by the Surgeons of the American Expeditionary Force in Siberia, have been of much interest because of the new forms they contained, and the specimens have usually been in excellent condition, so that it has been comparatively easy to differentiate them.

While there have been some smaller species as a rule the forms have been large, heavily scaled, and more hirsute than the species from the more southern areas. Among these new forms are two Anopheles belonging to the maculipennis group, $i . e$. with spotted wings, very closely allied, yet showing differences which, because the Siberian forms are not well known, it seems desirable to consider specific, and both are described below.

Anopheles lewisi sp. nov.

Female. Head light brown with a median bunch of white forked and lanceolate scales, and long slender white scales on the vertex projecting forward, brown forked scales on the occiput and sides, light bristles on the vertex, brown ones around the eyes; antennæ dark brown, basal joint brown with a few flat brown scales, verticels brown, scanty, and short, the pubescence is white; proboscis brown, labellæ brown; palpi brown, the proximal joint heavily brown scaled, the following not so dark and the scales appressed, short brown hairs on the ultimate and penultimate joints and a few at the apex of the antepenultimate; clypeus light brown, pruinose; eyes dark.

Thorax; prothoracic lobes light brown, covered with light to brown bristles; mesonotum has broad greyish median stripe reaching from the nape to the scutellum, immediately laterad a broad dark brown stripe extending from the scutellum cephalad about 

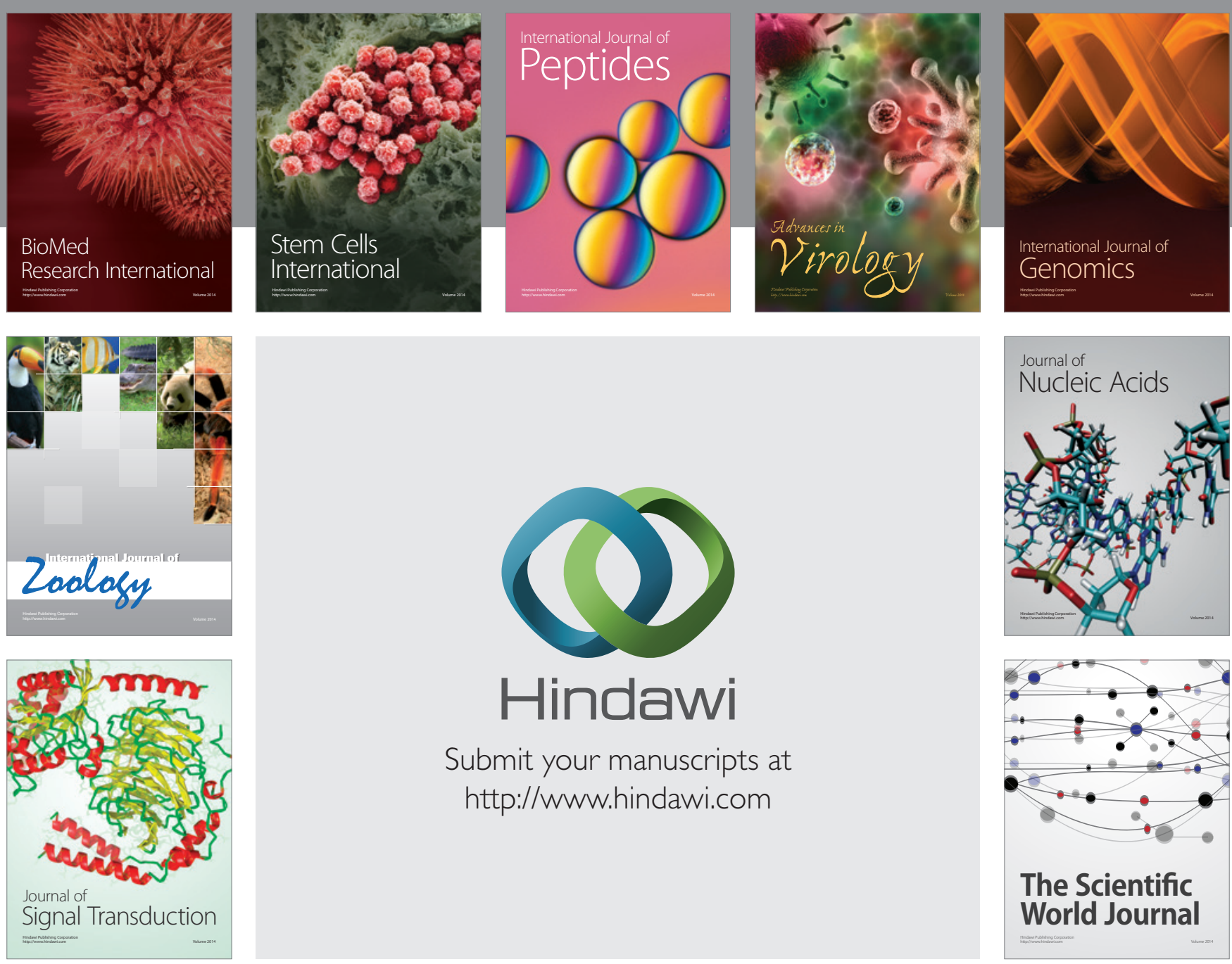

Submit your manuscripts at

http://www.hindawi.com
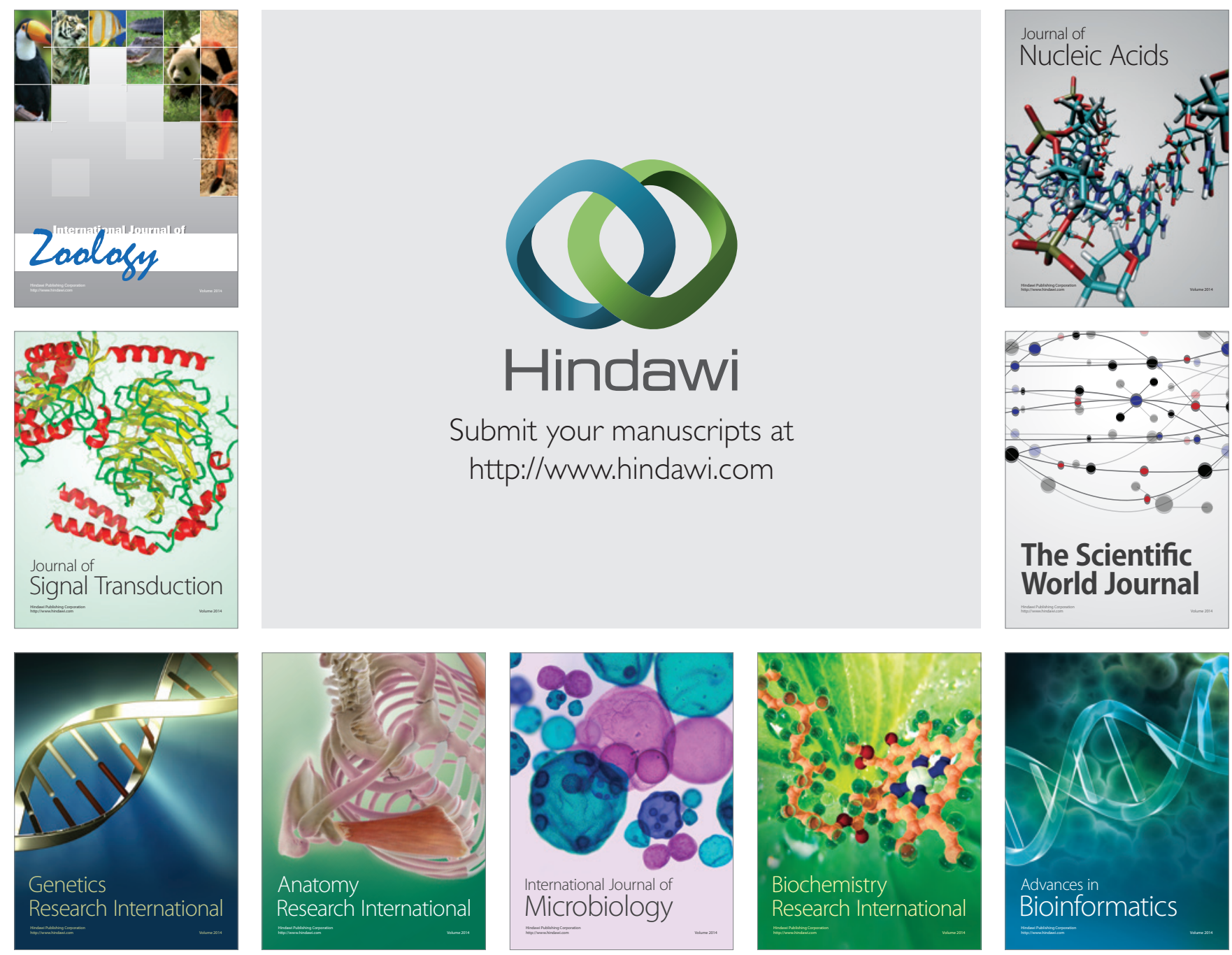

The Scientific World Journal
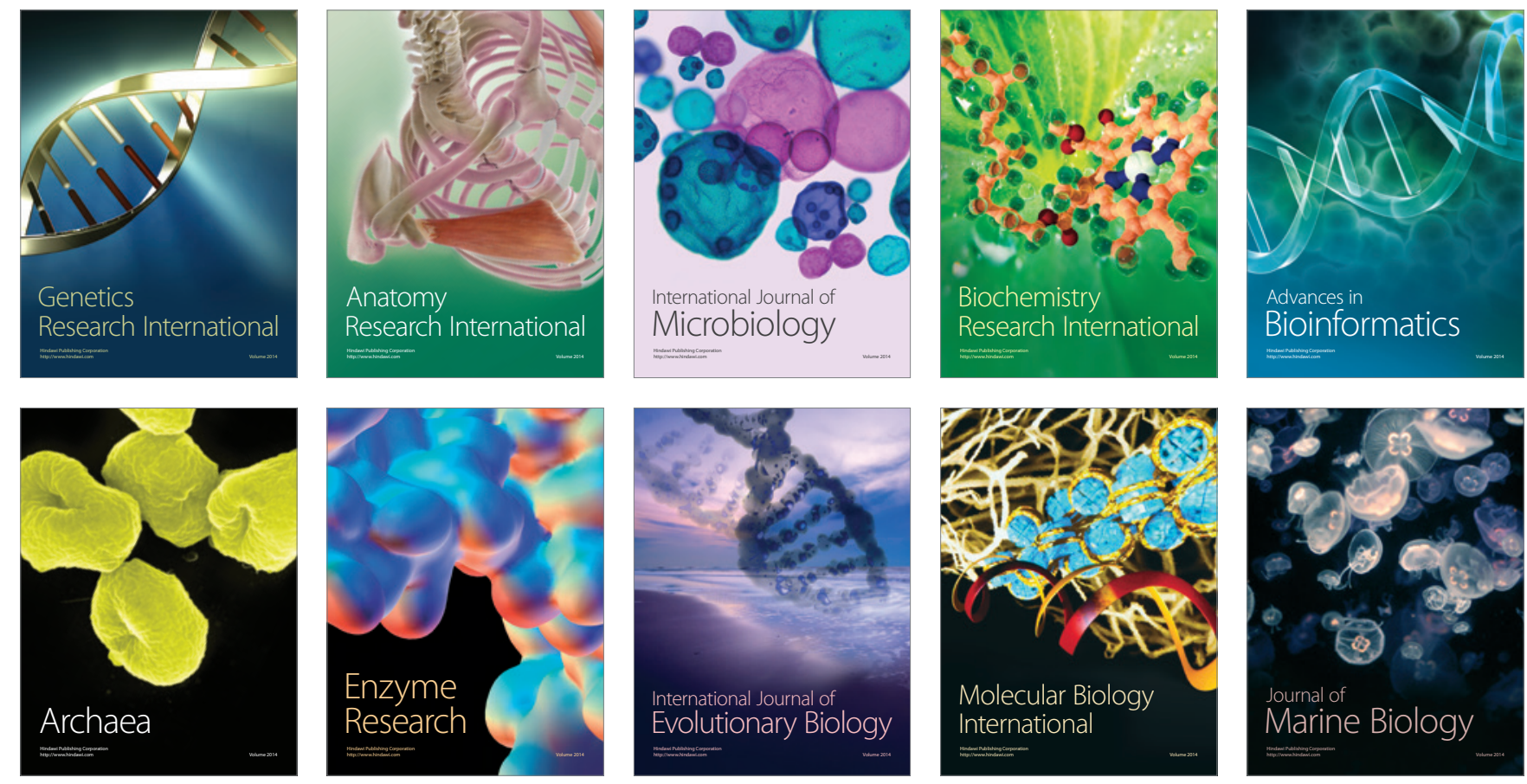